\title{
Rice husk as a potentially low-cost biosorbent for heavy metal and dye removal: an overview
}

\begin{abstract}
Rice husk as a low-value agricultural by-product can be made into sorbent materials which are used in heavy metal and dye removal. It has been investigated as a replacement for currently expensive methods of heavy metal removal from solutions. Currently, the study of rice husk as a low-cost sorbent for removing heavy metals has regained attention. The heavy metals being studied are: $\mathrm{As}(\mathrm{V})$ [1], $\mathrm{Au}$ [2,3], $\mathrm{Cr}(\mathrm{IV})$ [4], $\mathrm{Cu}$ and $\mathrm{Pb}$ [5,6], $\mathrm{Fe}, \mathrm{Mn}, \mathrm{Zn}, \mathrm{Cu}$ [7] and $\mathrm{Cd}(\mathrm{II})$ [8ї 10]. Rice husk is also being used to treat textile dyes such as like malachite green [11,12] and acid yellow 36 [13]. The treatment and preparation of rice husk activated carbon are of importance and became a subject of study [14ї 16]. In this review an extensive list of previous and current literature on rice husk activated carbons in removing heavy metals and dyes, their preparation or treatment and isotherms studies were complied to provide a summary of available information on rice husk and its potential as a low-cost sorbent.
\end{abstract}

Keyword: Rice husk; Heavy metals; Adsorption; Dye; Isotherms; Sorbents 